\title{
Amor e um prato de momo: Traduções dos poemas da Tenzin Tseyang Gonsar
}

\author{
Tais Leite de Moura
}

\begin{abstract}
Resumo: O presente trabalho apresenta traduções poéticas de dois poemas da tibetana Tenzin Tseyang Gonsar: "Momo Love" ("Amor momo") e "Momo burp" ("Arroto momo”) expressando, através de um prato típico, um sentimento de intimidade e familiaridade. As traduções são acompanhadas de informações sobre a autora, algumas interpretações possíveis dos poemas e o processo de tradução.
\end{abstract}

Palavras-chave: Tenzin Tseyang Gonsar; comida Tibetana; amor

\begin{abstract}
This work presents poetic translations of two poems by the Tibetan poet Tenzin Tseyang Gonsar: "Momo Love" and "Momo burp" expressing, through a typical dish, a feeling of intimacy and familiarity. Both translations are followed by information on the author, some possible interpretations of the poems, and the process of translation.
\end{abstract}

Keywords: Tenzin Tseyang Gonsar; Tibetan food; love 


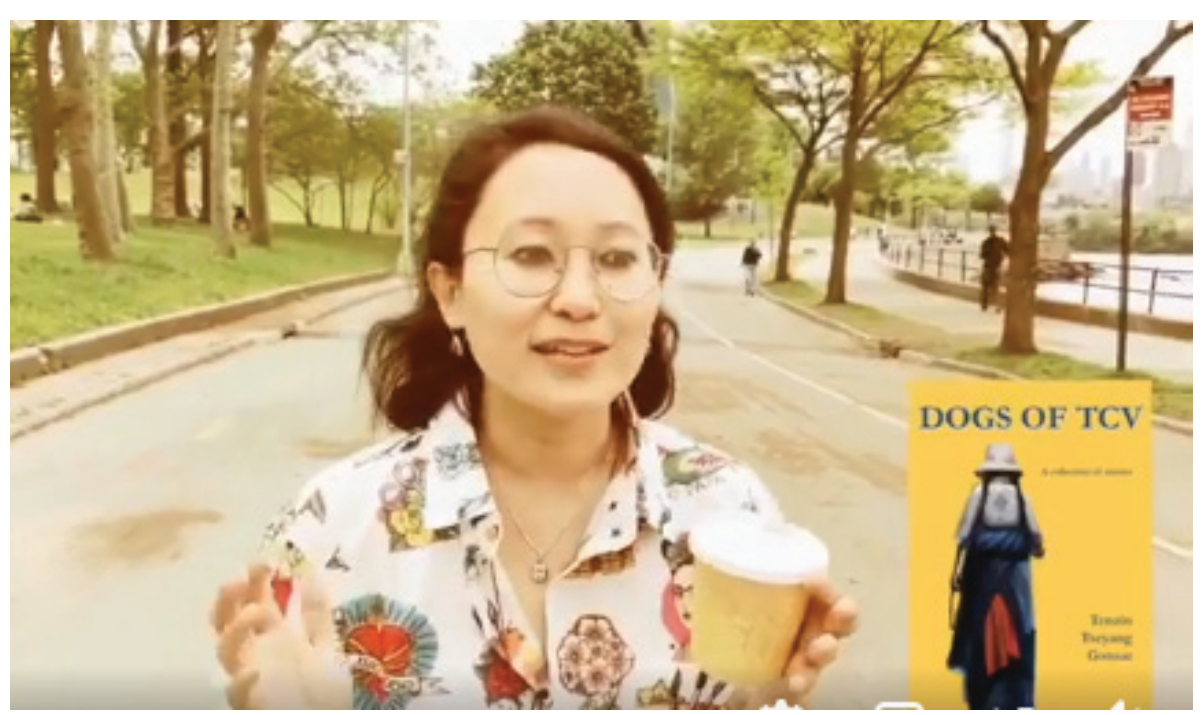

\section{A autora}

Tenzin Tseyang Gonsar é uma escritora tibetana exilada, que trabalha como analista de pesquisas de saúde na cidade de Nova Iorque. Cresceu em Dharamsala, a capital do exílio dos tibetanos na Índia, e frequentou a escola de refugiados conhecida como Vila das Crianças Tibetanas (Tibetan Children's Village - TCV). Tem boas lembranças de passar o tempo e se perder nos livros das bibliotecas da TCV. Ela espera trabalhar para alcançar seu pequeno sonho de criar um mundo onde as crianças tibetanas vão para as bibliotecas e encontram livros escritos por escritores tibetanos - de personagens com nomes tibetanos, de encontrar mundos criativos onde o herói, anti herói, ou mesmo o vilão é tibetano. Em outras palavras, Tseyang aspira por histórias que são distintivamente tibetanas em sua essência, mesmo se escritas em inglês. Seu primeiro livro Cães da TCV (Dogs of TCV) foi publicado em $2020^{1}$.

Como foi possível entrar em contato com a autora durante o processo de tradução dos poemas, indaguei sobre o significado de alguns vocábulos e sobre a

1 GONSAR, Tenzin Tseyang. Tibet Writes, 2020. Disponível em: < https://www.tibetwrites.in/authors/ tenzin-tsevang-gonsar/> Acesso em: 29 de julho de 2020. 
importância do momo para Tseyang. Ela prontamente respondeu, fato que enriqueceu as interpretações dos poemas. Tais informações podem ser encontradas ao longo desta tradução comentada.

\section{Momo}

Ambos os poemas apresentam "momo" no título e são permeados de referências a ele - seja no tema ou ao longo dos versos. Portanto, minha primeira questão foi a seguinte: o que é momo? Momo é considerado o prato oficial do Tibete, e consiste de uma massa de farinha branca que envolve um recheio quente cujo sabor pode variar desde carne de porco, vegetais e até tofu. Ele pode ser frito ou feito no vapor, pode ser servido em uma cesta de vime em restaurantes ou vendido em barracas pelas ruas, e é irresistível. (HAUZEL, 2017) ${ }^{2}$

A palavra em português que poderia substituir "momo" seria "bolinho". Contudo, essa comida não é típica do Brasil e culturalmente não tem o mesmo peso que o momo no Tibete. Afinal, pela leitura dos poemas é possível notar um amor imensurável pelo prato, e não se pode dizer o mesmo de um bolinho neste país. Portanto, decidi manter o substantivo em sua língua original.

De acordo com Tseyang,

Momo é minha comida predileta no mundo todo. Momo, para mim, não é somente um prato [...] Momo é tradicionalmente a comida mais favorita de todos os tibetanos, e apesar de haver discussões conflitantes sobre sua origem, todos irão dizer que o momo é uma comida essencialmente tradicional tibetana. Durante minha vida, quando havia uma comemoração em casa, na escola, ou em qualquer lugar da comunidade tibetana, o momo era servido e era considerado o mais especial. Fazer momo não é tarefa para uma pessoa só. Quando fazemos momo, são necessárias várias funções e a família inteira sentava junta, conversando e compartilhando esse momento feliz juntos. Momo une as famílias tibetanas e cria felicidade. Eu associo ele com [...] todas as coisas boas. ${ }^{3}$

2 HAUZEL, H. The Story of Momos: What makes this Tibetan dumpling so popular? Ndtvfood,

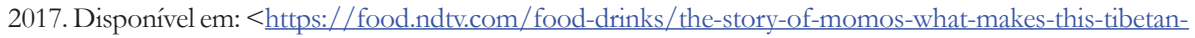
-dumpling-so-popular-1397480> Acesso em: 29 de julho de 2020.

3 TSEYANG, Tenzin. [Entrevista concedida a] Tais Leite de Moura. 10 ago 2020. 
A declaração deixa claro o papel que o momo tem na vida dos tibetanos; tal sentimento de familiaridade e terra natal percorre "Amor momo" e "Arroto momo", como veremos a seguir, com as versões originais em inglês e as traduções para o português brasileiro.

\section{Momo love}

Love, you ask me? I'll tell you

my love for you is like a plate of momo

Hot, greasy - sincerely heavy at the core

Socially disguised, however, by a perfectly thin

dough of self-preserving ego

Each bite awakening sensuous feelings galore

Alas, with only eight pieces a universe -

never enough!

\section{Amor momo}

Amor, você me pergunta? Eu te digo

meu amor por você é como um prato de momo

Quente, gorduroso - sinceramente pesado no meio

Socialmente disfarçado, entretanto, por uma perfeitamente fina

massa de ego que se auto preserva

Cada mordida despertando sentimentos sensuais em abundância

Infelizmente, com somente oito pedaços no universo -

nunca o suficiente!

\section{O poema}

“Amor momo" é um poema composto de nove curtos versos livres. É iniciado com uma pergunta; depois, as comparações entre amor e um prato de momo são constantes até o seu encerramento. Por isso a decisão de manter os termos culinários na tradução como no original: "hot - quente", "greasy - gorduroso", "heavy - pesado", "dough - massa". Utilizei o termo "pesado" para "heavy" 
pois este pode ser uma alusão ao sentido literal de um prato com oito momos recheados, e no sentido figurado de um alimento gorduroso que dá a sensação de "pesar" no sistema digestivo após sua ingestão.

Como o poema mimetiza um discurso durante uma conversa informal, coloquei "Eu te digo" como a versão de "I'll tell you"; ainda que a sentença em sua língua original esteja no futuro, traduzir por "Eu vou te dizer" ou "Eu te direi" pareceu inconsistente com o restante do texto.

O vocábulo "sincerely" é regularmente empregado para finalizar cartas e e-mails, e em uma tradução inicial seria "atenciosamente". Entretanto, neste caso tal versão é inaceitável dado o contexto do poema e a posição na sentença. Decidi por substituir o termo por uma versão mais parecida com a língua portuguesa, "sinceramente" para enfatizar o peso do prato de momo e do amor do eu-lírico pela comida e por uma pessoa.

O termo "alas" pode expressar uma interjeição - "Ai de mim" - ou “infelizmente, lamentavelmente". Como descobri através de minha conversa com Tseyang, na Índia, onde a autora cresceu, o padrão são dez pedaços de momo por prato. Entretanto, nos EUA, onde Tseyang mora há cerca de quatro anos, um prato de momo contém oito pedaços. ${ }^{4}$ Surge então a questão sobre o número de pedaços em um prato de momo: aqueles que cresceram na Índia acostumados com uma referência sentem que oito nunca serão o suficiente, como o último verso afirma com convicção. "Infelizmente" transmite essa decepção no poema, por isso foi o vocábulo escolhido.

"Amor momo" é curto, mas assim como o prato tibetano que o nomeia, é recheado de significado. A pergunta inicial apresenta uma natureza retórica: o eu-lírico a realiza e a responde, listando os motivos que o levam a crer que o sentimento que ele tem por algo ou alguém é amor. $\mathrm{E}$ a analogia encontrada por ele para expressar o que sente é a iguaria momo: sua massa, seu recheio, o prato onde é colocada e o fato de que a porção nunca parece suficiente, pois sempre queremos mais. O sentimento é descrito como pesado, quente e gorduroso, características que podem ser negativas tratando-se de comida. Contudo, isso não quer dizer que ele não possa ser desejado e consumido em grandes quantidades, se associarmos tais características a comidas do tipo fast food, ou mesmo àquela receita de família que é pesada, gordurosa e quente, mas é adorada por todos.

4 Idem 3. 
O amor é um sentimento carregado de opostos: é capaz de causar sofrimento e felicidade na mesma proporção. Seja ele recíproco ou unilateral, ou ocorrendo em diferentes núcleos sociais, existem inúmeras situações e períodos pelos quais um indivíduo passa ao experimentar tal sensação.

Neste caso, o amor aparenta pertencer ao cotidiano, é familiar, produz um sentimento de lar - ainda mais quando consideramos o fato da autora ser uma tibetana exilada. O prato de momo é sua identidade, despertando emoções felizes e talvez por vezes melancólicas: compartilhar um momento com alguém que amamos ao comprar momo nas ruas; um encontro entre amigos em que compartilham um prato de momo; uma comemoração em família cujo aperitivo é momo. O amor ganha esse peso de rotineiro, mas sinceramente significativo.

\section{Momo burp}

once upon a late night run, in between happy hour and warm bed after marathon of sweet nothings before entwining of clammy hands things detoured to the disordered jackson heights - the chaos of it for the single commonality in between their love for momo the ricketier the stall the better a kiss was dropped somewhere amid the fifth chives it was - after the regular questioning, long - hopeful eyes "well I love you too", the reply "but as much as you love momo?" glass door of potala shack broke open gushing mixed breath of meaty garlicky fragrance as one burped - YES in response. 


\section{Arroto momo}

era uma vez, em uma correria de fim de noite, entre o happy hour e a cama quentinha depois da maratona de doces nadas antes do entrelaçar de mãos pegajosas as coisas desviaram-se para o desordenado jackson heights - o caos dele pela única convergência entre ambos seu amor por momo quanto mais frágil a tenda, melhor um beijo foi dado em algum lugar entre a quinta cebolinha era - depois do regular questionamento, longos - olhos esperançosos "bem, eu te amo também”, a resposta "mas tanto quanto ama momo?" a porta de vidro da barraca potala escancarou-se soprando uma lufada misturada de fragrância impregnada de alho enquanto arrotava - SIM em resposta.

\section{O poema}

"Arroto momo" é um desdobramento de "Amor momo", pois coloca o prato tibetano em uma situação amorosa, e o tom cotidiano é descrito em detalhes, pintando uma cena na mente de seus leitores. É bem-humorado e familiar ao mesmo tempo, descrevendo uma conversa descontraída e seus arredores, que gira em torno de momo. São dezessete versos curtos e livres, e todos os substantivos estão em letra minúscula, mesmo aqueles que denominam nomes próprios.

A palavra "run" pode significar "corrida" ou "correria". Inicialmente pensei que o termo se referia a um exercício físico no cotidiano, uma corrida noturna pelo bairro. Mas os versos seguintes revelaram que o eu-lírico falava sobre a agitação do dia-a-dia, ao citar um local agitado em Nova Iorque, uma refeição comida às pressas, por isso a tradução por "correria".

A primeira expressão que me chamou atenção durante a tradução foi “jackson heights”, pois me pareceu um local relevante para o eu-lírico. E após 
uma investigação, foi possível compreender o motivo da menção ao lugar, e sua relação com a autora tibetana exilada.

Jackson Heights é uma vizinhança dentro do Queens, em Nova Iorque, conhecida por seus habitantes em sua maioria imigrantes (cerca de 62\%). Os nova-iorquinos geralmente associam o bairro à Índia, dada a quantidade de indivíduos da região do sul da Ásia presente no local, assim como a culinária em evidência. Contudo, o distrito tem recebido um número crescente de tibetanos desde 1992, que foram capazes de conceber seu "pequeno Tibet" no local. (LI, 2019) ${ }^{5}$

Diferente dos outros grupos de imigrantes do bairro, os tibetanos mantiveram muitos aspectos de sua cultura. Li (2019) explica: “(...) transformaram-no [Jackson Heights] em um reflexo de sua terra natal, abrindo templos, restaurantes, lojas e centros que ensinam a língua tibetana" ". Deste modo, o distrito pode ser considerado um "lar longe do lar", pelo menos em relação aos tibetanos diaspóricos.

Um termo desafiador de transpor para o português brasileiro foi "ricketier", pois não é comum na língua inglesa. O eu-lírico empregou o termo "rickety" na estrutura comparativa, adicionando "er" ao final da palavra. A primeira tradução é "raquítico", mas como no português essa característica é geralmente dada a pessoas, preferi pelo termo "frágil" comumente utilizado para caracterizar objetos inanimados.

"Potala" foi um vocábulo cuja tradução incialmente não encontrei. Foi esclarecido por Tseyang: "Potala é o nome de um restaurante de momo famoso em Jackson Heights [...] um restaurante tipo fast food onde você se senta e come rapidamente" . Portanto, ele não sofreu mudanças para a versão em português. Apesar de ser um restaurante ao invés de uma tenda, Potala provavelmente foi retratado desta maneira com a intenção de complementar a essência familiar do poema.

Por fim, o termo "garlicky" é uma construção do eu-lírico para salientar o ar impregnado do local onde ele e seu locutor se encontram. A palavra "garlic", que significa "alho", foi transformada em um adjetivo acrescentando-se a letra "y", ato muito comum para qualificar alimentos na língua inglesa. Um substantivo

5 LI, Michelle. The Preservation Trail: How Tibetans Formed Their Own "Little Tibet" in Jackson Heights, 2019. Disponível em: $<$ https://storymaps.arcgis.com/stories/7df79174517f4c0da27 ab4f23ecda7cb $>$ Acesso em: 10 de agosto de 2020.

6 Idem 5.

7 Idem 3. 
recebe a letra "y" que age como um sufixo para a descrição de comida: "buttermanteiga" transforma-se em "buttery - amanteigado"; "juice - suco" em "juicy - suculento"; "pepper - pimenta" em "peppery - apimentado" e assim por diante.

"Arroto momo" é curto, bem-humorado e descreve uma situação banal: uma escapada em um dia da semana de um casal para comer momo em Jackson Heights. É possível deduzir tais informações através das descrições do poema nos versos "entre o happy hour e a cama quentinha" e "depois da maratona de doces nadas". Os "doces nadas" seriam as variadas situações do trabalho, que podem parecer vazias com o passar do tempo.

Tseyang conta a história de tal encontro:

Esse poema foi escrito logo após um encontro romântico. Havíamos planejado ir para um lugar chique na cidade, mas acabamos indo para um restaurante pequeno em Jackson Heights [...] sendo honestos com nós mesmos [...] e declaramos nosso amor um pelo outro ${ }^{8}$

Através da afirmação acima, entendemos que o casal é formado por tibetanos diaspóricos. O amor por momo é a principal afinidade entre eles, de acordo com os versos "pela única convergência entre ambos/ seu amor por momo". Considerando-se a situação de ambos os indivíduos, é possível compreender o significado do prato para eles. Deliciar-se com a iguaria é um retorno ao lar, é conectar-se com uma parte da sua identidade que nunca será completamente apagada.

Mesmo que durante o dia eles tenham que adaptar-se à sua nova residência, com novos costumes, uma nova língua e uma nova cultura, ainda tem Jackson Heights. Lá encontram barracas, aromas e comidas familiares, além de poderem utilizar sua língua de origem.

Eles se sentem à vontade comendo momo; tanto isso que um deles arrota "sim" em resposta à pergunta sobre o amor dos dois. O humor ocorre pelo uso do verbo "arrotar", porém a situação revela também um grau de intimidade entre o casal, evidenciada quando eles estão mais relaxados, aproximados do Tibete.

Dada a descrição de um local e um alimento que destaca a cultura tibetana, "Arroto momo" é um poema sobre o amor à sua identidade diaspórica, seu local e seu eu de origem. Apesar do amor romântico estar presente no diálogo exposto

8 Idem 3. 
nos últimos versos e na intimidade em que o casal vive em frente à uma tenda em uma rua lotada, o título e a sensação suscitam uma familiaridade que só pode ser entendida no seu lar.

\section{A tradução e sua importância}

Para iniciar o processo de tradução, li e reli os poemas algumas vezes para assimilar seus tons e conteúdos, seguido por uma versão inicial com os termos já conhecidos por mim. Para uma versão mais completa, procurei os termos aqui citados em textos e sinônimos que mais se relacionassem à comida. Por fim, uma conversa com a autora esclareceu sobre algumas expressões e sobre os poemas.

Este é meu segundo contato com uma obra de um cidadão tibetano exilado: traduzi informalmente dois poemas de Tenzin Tsundue, ativista ganhador do prêmio Outlook-Picador de não-ficção em 2001. Nas duas vezes, encontrei-me envolvida com a situação e imersa no conteúdo dos textos. A tradução de "Amor momo", "Arroto momo" e dos outros poemas inseridos neste livro contribui para a heterogeneidade de obras no Brasil, e consequentemente de temas a serem explorados artisticamente. Através desta compilação, dá-se relevância à discussão política sobre o Tibete aqui, considerando as adversidades e contrariedades da diáspora contínua desta região autônoma.

Tais Leite de Moura é brasileira, pedagoga e mestre em Letras pela Universidade de São Paulo. Sua dissertação teve como foco as transgressões das minorias no romance "O Deus das Pequenas Coisas" (1998), de Arundhati Roy. Participou do projeto SPeCTReSS (Social Performance, Cultural Trauma and Reestablishing Solid Sovereignties) para aprofundar-se no tema do trauma cultural, e através dele realizou um intercâmbio em Tartu, na Estônia. Atua como professora de inglês e é organizadora do grupo de estudos "Lendo a Índia" no Centro Cultural Swami Vivekananda em São Paulo. 